\title{
Optimal Design of Loitering Munition Trajectory in Complex Battlefield Environment
}

\author{
Xuancen Liu ${ }^{1, a}$, Longbin Liu ${ }^{1, b}$, Min Xiang ${ }^{1, ~ c}$, Weihua Zhang ${ }^{1, d}$ \\ ${ }^{1}$ College of Aerospace Science and Engineering, National University of Defense Technology, \\ Changsha, 410073, China \\ aemail: 335420411@qq.com, bemail: longbuaa@163.com, cemail: xiangmin333@hotmail.com, \\ demail:zwh_kjs@163.com
}

Keywords: Loitering Munition; Battlefield Environment; Launch Angle; Trajectory Optimization

\begin{abstract}
Loitering munitions would quickly reach the target area in the complex battlefield environment, and perform a variety of application advantages, such as total field reconnaissance, flexible cruise monitoring, weather monitoring, the battlefield damage assessment, relay communication and target attack, which has attached the widespread attention around the world. In this paper, each functional system model of the typical loitering munitions has been established. With the fact that the loitering munitions are faced with the problem of complex terrain, its launch battlefield environment and launch strategies under different terrain is analyzed and studied. And through the wind tunnel test of aerodynamic characteristics, the dynamic model of a small loitering munition is developed. In a typical topographical environment, based on genetic algorithm, trajectory optimization for a launch loitering munition is accomplished, eschewing the battlefield obstacles, the calculation results have great significance in technical guidance to engineering practices.
\end{abstract}

\section{Introduction}

Loitering munition is a new concept of information weapon which is able to launch quickly and flexibly. According to the combat mission and the battlefield situation, the "cruise flight" can be realized over the target area to execute a variety of missions. This kind of new concept weapon is the combination of unmanned aircraft and missile technology, which can be flexibly deployed to the battlefront and shows a variety of functions, such as reconnaissance, damage assessment, precise attack, communication, early warning, etc [1]. With long-time cruising ability, the loitering munition has significant advantage on hitting blind enemies at the ridge, roof and so on, which can greatly reduce the number of casualties. Such ammunition has aroused widespread attention in recent years and many countries such as America, Britain and Israel have carried out the research work. A small loitering munition "Switchblade" made by the United States AeroVironment company has armed American soldiers and was successfully applied on the battlefield in Afghanistan. With high evaluation from the U.S. Army, the success of "Switchblade" and its practical application, marked the loitering munitions capable of reconnaissance/attack integration have been used into combat phase. Loitering munitions provide a new way of fighting for the future military action, which makes the rapid deployment of weapons over the target area [2][3]. In recent years, countries according to their different need focus on the research of loitering munitions. There are some new trends in the development of loitering munitions, such as network cooperative engagement, composite guidance system, people in the loop control and low-cost munitions [4].

\section{Analysis of Loitering Munition System}

The whole system is composed of missile body, ground stations and launch device, as shown in figure 1. Users of loitering munition control the route and search path through ground station. The missile body with detection instruments and small warheads can be folded inside the launcher. 
When users launch the loitering munition, wings provide lift in the air and the propeller provides thrust for the loitering munition to cruise over the target area.

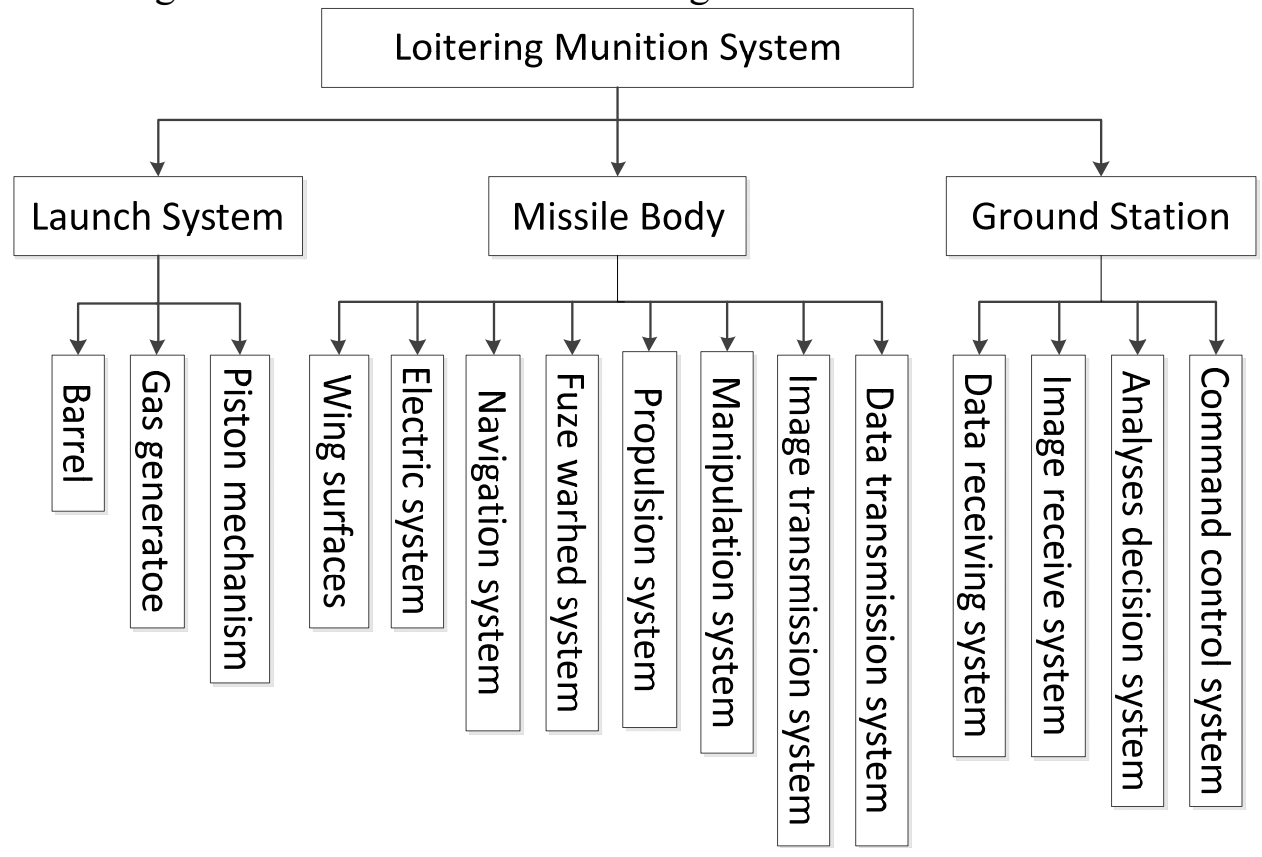

Fig.1. Loitering Munition System

When climbing along the trajectory to a certain height, wings, tails and the engine start working at the same time. According to certain search strategy, the loitering munition flies along the route to the target area and carry out various operations over the target area [5]. Loitering munitions are usually stored in the launcher, which is easy to transport and carry. The launcher is made up by the barrel, base and stent (two support pole), as shown in figure 2 .

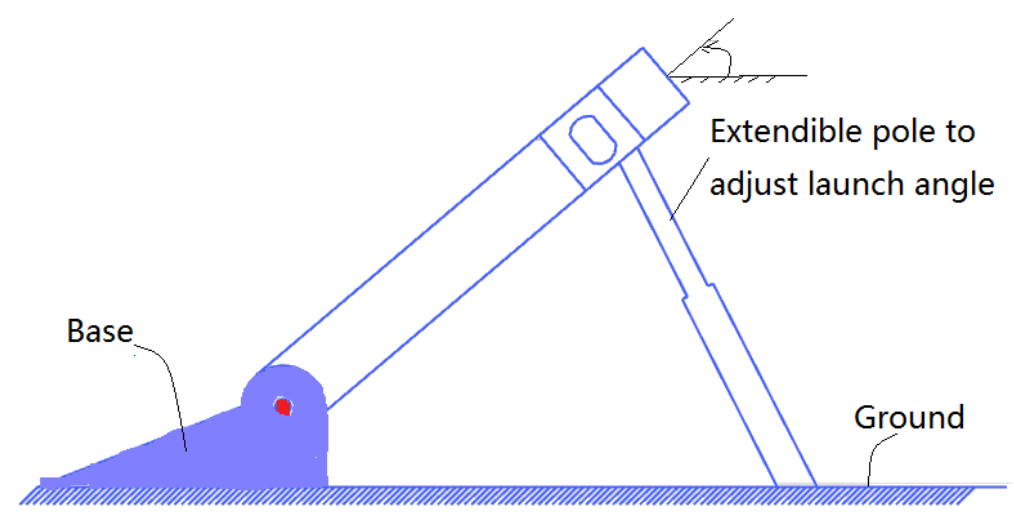

Fig.2. The Launch System

The base is set up to fix the launch system and the extendible poles are used to adjust launch Angle and make the launcher stable.

\section{Analysis of Loitering Munition Launch Environment}

In future military action on or fight against terrorism, loitering munitions are used to provide real-time precise weapons for small-scale ground troops, which improves the security of the soldiers and effectively reduces the number of casualties [6]. Some loitering munition is more complex, such as the United States FASM/Quicklook, which used the folding inflatable wing to fly [7]. However, when users launch the loitering munitions, the battlefield environment is very complex, such as mountains, forests, canyons, towns, rivers. Complex terrain in the battlefield environment makes it more difficult for the climbing of loitering munitions. Wind direction and speed will also make loitering munitions' launch more and more difficult. If in the process of climbing, the loitering 
munition has crashed onto obstacles such as trees, mountains, buildings, the users will lose one shot.

Based on technology of computer simulation, virtual battlefield environment can be established. In different virtual battles, users can be trained to adapt to complex battlefield environment [8]. In the training process, operators need to analyze the current battlefield terrain, wind direction, wind speed and the characteristics of the target to make reasonable decisions. Its decision-making process is as shown in figure 3.

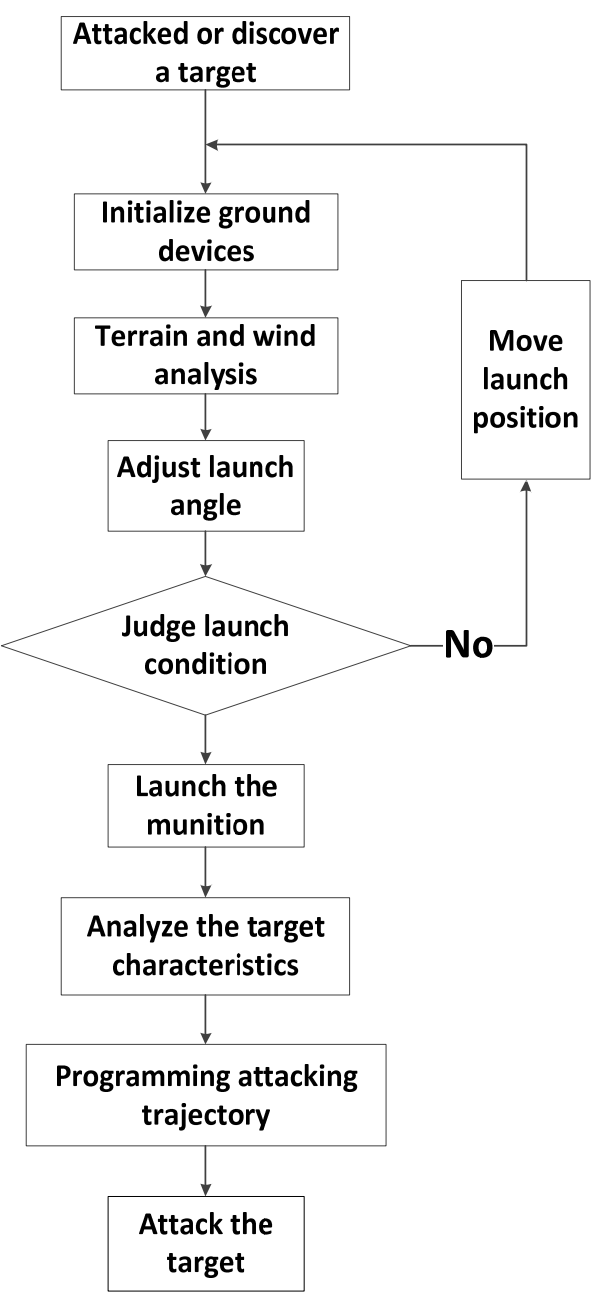

Fig.3. Decision-making Process

As shown in figure 3, while the operator is preparing to launch the loitering munition, the battlefield environment is supposed to be carefully analyzed. If the launch is not allowed, the operator should change the launch angle and position. After launch, operations need to analyze the characteristics of the target area in real time, determine a reasonable search strategy. When the characteristics of target have been analyzed, the operator needs to plan a reasonable attack ballistic to complete the mission. 


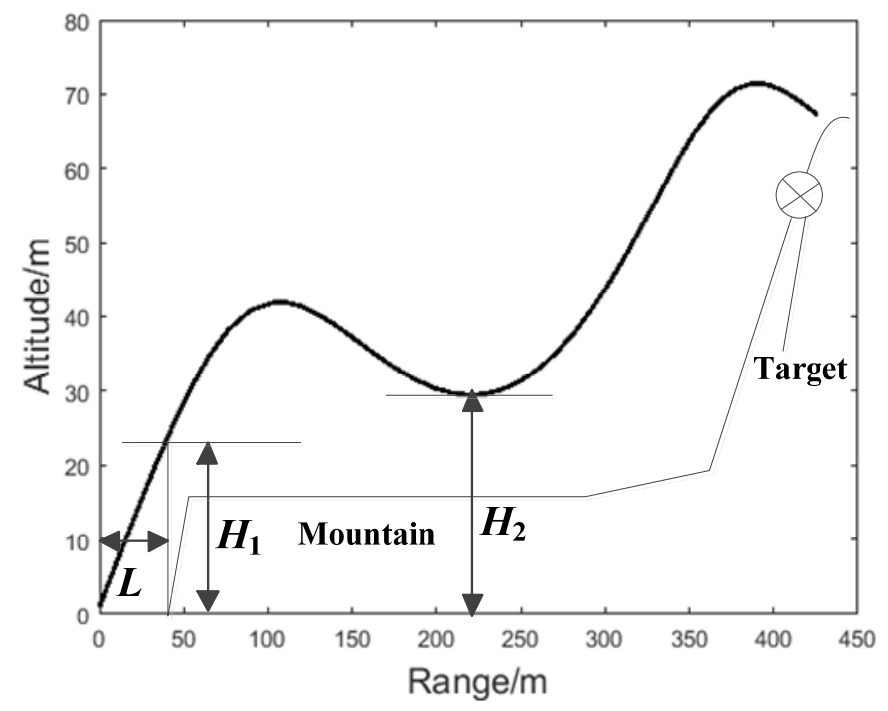

Fig.4. Analysis of a Possible Terrain

Figure 4 shows a possible battlefield environment, when suffered sudden attack from enemies at the ridge, the loitering munition is launched to attack the target. But in this situation, the launch angle must be carefully adjusted fly over the highland before the target. $\mathrm{L}$ is the distance between the highland and launch position. $H_{1}$ and $H_{2}$, represents the two positions' height, which are most likely to hit obstacles in this trajectory.

\section{Flight Program and Trajectory Optimization}

In this paper, the launcher is set up to adjust the launch angle. The loitering munition climbs according to the Angle of attack programs and then maintains stability of a certain Angle of attack, flight procedures are as follows:

$$
\varphi_{p r}(t)= \begin{cases}\theta_{\text {launch }} & 0 \leq t \leq t_{1} \\ \theta_{v}+\alpha(t)+\omega_{e z} t & t_{1}<t \leq t_{2} \\ \theta_{v}+\alpha_{\text {steady }}+\omega_{e z} t & t_{2}<t\end{cases}
$$

In this formula, $\varphi_{p r}$ for the pitch angle; $t_{1}$ for the time when the loitering munition left launcher, here $t_{1}=1 \mathrm{~s} ; \theta_{\text {launch }}$ for launch Angle; $\theta_{v}$ for slope angle; $\alpha_{\text {steady }}$ for the angle of attack in the period of steady climbing; $t_{2}$ for the start time of steady climbing; $\alpha(t)$ to :

$$
\alpha(t)=\alpha_{\text {steady }} \frac{t-t_{1}}{t_{2}-t_{1}} \quad t_{1}<t \leq t_{2}
$$

First of all, based on the flat earth hypothesis, the 3-dof model of a certain type of loitering munition is established, ignoring the rotation of the earth [9]. It is supposed that the launch speed of the loitering munition is $30 \mathrm{~m} / \mathrm{s}$. The distance L between the launch position and highland in figure 4 is $40 \mathrm{~m}$.

For the terrain in figure 4 , according to the flight procedures, the launch angle $\theta_{\text {launch }}$, time $t_{2}$ and the angle of attack $\alpha_{\text {steady }}$ are taken as the design variables for optimization, the range of these variables as shown in table 1 . 
Table 1 The respective maximum and minimum bounds of design variables for loitering munition trajectory optimization

\begin{tabular}{ccc}
\hline Variable & Lower limit & Upper limit \\
\hline$\theta_{\text {launch }}\left({ }^{\circ}\right)$ & 10 & 80 \\
\hline$\alpha_{\text {steady }}\left({ }^{\circ}\right)$ & 1 & 6 \\
\hline$t_{2}$ (s) & 12 & 30 \\
\hline
\end{tabular}

In order to fly over the highland in safest situation, the maximum value of the smaller one between $\mathrm{H}_{1}$ and $\mathrm{H}_{2}$ is set as the objective function:

$\max \quad H_{\text {safe }}=\min \left(H_{1}, H_{2}\right)$

\section{Test results}

Based on the genetic algorithm, the results are as follows:

Table 2 The result of trajectory calculation in different launch angle

\begin{tabular}{|c|c|c|c|c|}
\hline Condition & $\begin{array}{c}\text { Launch } \\
\text { Angle }\end{array}$ & $\mathrm{H}_{\mathbf{1}} / \mathrm{m}$ & $\mathrm{H}_{\mathbf{2}} / \mathrm{m}$ & $\operatorname{Min}\left(\mathrm{H}_{\mathbf{1}}, \mathrm{H}_{2}\right)$ \\
\hline 1 & $15^{\circ}$ & 11.2 & None & 11.2 \\
\hline 2 & $20^{\circ}$ & 15.0 & None & 15.0 \\
\hline 3 & $25^{\circ}$ & 19.1 & 34.4 & 19.1 \\
\hline 4 & $30^{\circ}$ & 23.6 & 29.5 & 23.6 \\
\hline 5 & $35^{\circ}$ & 28.7 & 23.7 & 23.7 \\
\hline
\end{tabular}

We can see from the table 2, with the increase of firing Angle, $H_{1}$ has a significant increase, while $\mathrm{H}_{2}$ gradually decreases, and the jump of the ballistic becomes more and more obvious. When obstacles are near the loitering munition launch position, such as a jungle terrain, it is more reasonable to choose a larger launch angle to launch the loitering munition, but should choose appropriate control law to ensure the safety of its decline period. When obstacles are far away from the launch position, but are like high hills, highlands and mountains, a smaller launch angle can be used to ensure the loitering munition have already climbed to the safety altitude when reaching the obstacle.

The optimal firing angle is as follows:

$$
\mu_{\text {optimal }}=32.8^{\circ}
$$

The maximum safe altitude is as follows:

$$
H_{\text {safe }}=26.3480 \mathrm{~m}
$$

The optimal ballistic curve is shown in figure 5, height and Mach along with the change of time are shown in figure 5(a), the slope angle of velocity changing with time is shown in figure $5(b)$. 


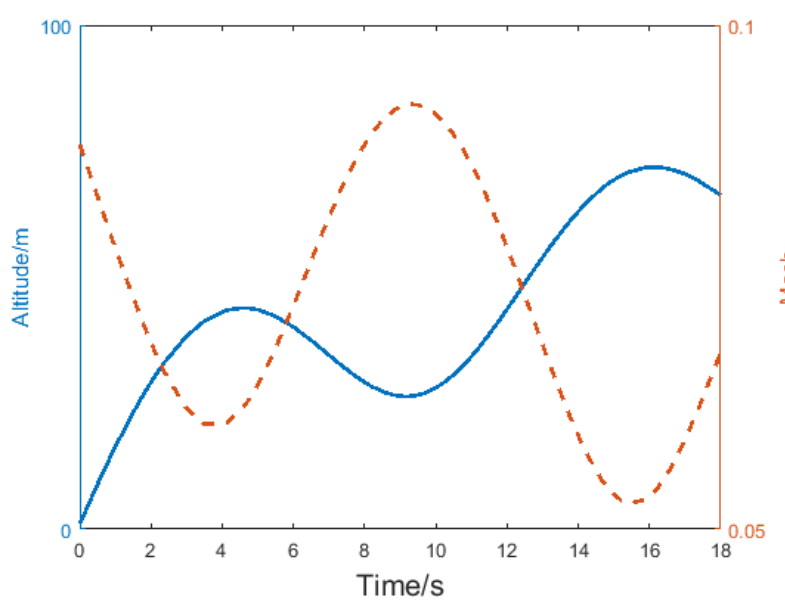

(a) Altitude and Mach with time

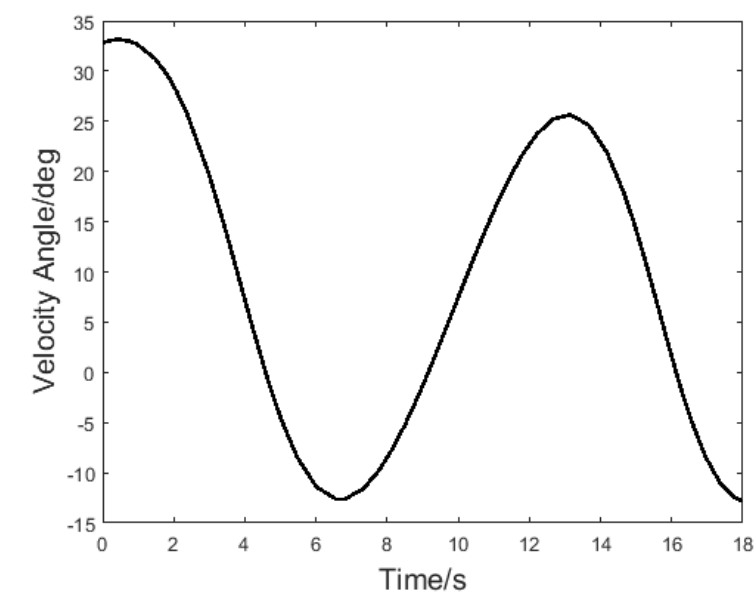

(b) local slope angel with time

Fig.5. Experimental results

\section{Conclusion}

Loitering munition, as integrative ammunition of reconnaissance and attack, is an important direction of the missile development in the future. Its application in the fight against terrorism is also very promising, which can greatly reduce the casualties and hit the blind target. In this paper the recent development of loitering munitions is introduced and dynamic model is established, analyzed and calculated when the loitering munition in complex battlefield environment. Based on computer simulation, the decision-making process of the training system for loitering munition is studied and established. The regularity of the trajectory with launch angle and other design variables is also studied by analyzing the computing results. Considering a typical terrain in the battlefield environment, the trajectory optimization of the loitering munition was carried out based on computer simulation and genetic algorithm. The optimal launch angle and safe height of the loitering munition under this circumstance was calculated. Research in this paper, provides important reference for loitering munitions' practical application, and the work on the loitering munition is of great significance.

\section{Acknowledgement}

In this paper, the research was sponsored by the National Natural Science Foundation of China (Project No. 51406230).

\section{References}

[1] Li Daguang. A New Information Munition-Loitering Munitions [J]. Technology Foundation of National Defence, 2009 (10) 36-39.(in Chinese)

[2] Bo Xifeng.RoboCup: American Soldier and a Small sword in Hand-Switch Blade [J]. Ordnance Knowledge, 2012 (8).(in Chinese)

[3] Bo Xifeng. Loitering munitions make indirect fire change revolutionized [J]. North-China in Time Information, 2009 (1) 9-11.(in Chinese)

[4] Pang Keyan, Han Lei, Zhang Minquan, ET al. Status and Devolopment Trends of Loitering Attack Missiles [J].Acta Armamentarii, 2010, 31(2) 149-152.(in Chinese)

[5] Zhang Jansheng. Foreign Loitering Munition Development Overview [J]. Aerodynamic missle Journal, 2015 (6).(in Chinese)

[6] Ji Xiuling, He Guanglin. Aerodynamic Characteristics of Gun-Launched Loitering Munitions 
and Its Shape Design [J]. Transactions of Beijing Institute of Technology, 2008, 28(11) 953-956.(in Chinese)

[7] Timothy R S, Erich M M, Mark K, ET al. Ballute and parachute decelerators for fasm/quicklook UAV,AIAA-2003-2142 [R]. California:[s.n.], 2003.

[8] Zheng Kangping, Xu Xianggan, Wang Zhanjun. An Algorithm for Estimating the Topographic Influence on the Helicopter Flying in Virtual Battlefield [J]. Computer Simulation, 2008,25(12) 81-83.(in Chinese)

[9] Chen Kejun, Liu Luhua, Meng Yunhe. Launch Vehicle Flight Dynamics and Guidance [M]. Beijing:National Defense Industry Press, 2014. 